\title{
O Ensino de Matemática no contexto da Educação inclusiva
}

\author{
The Teaching of Mathematics in the Context of Inclusive Education
}

\author{
Luciana Leandro Silva* \\ Instituto Federal de Educação, Ciência e Tecnologia de Roraima - IFRR \\ Andreia Aparecida Guimarães Strohschoen** \\ Universidade do Vale do Taquari - Univates
}

\begin{abstract}
Resumo
O presente artigo traz reflexão sobre a o ensino de Matemática no contexto da Educação Inclusiva. Os estudos que tratam sobre a atenção a pessoas com deficiência têm avançado nos últimos anos, trazendo uma compreensão melhor das formas de inclusão na escola. Objetivando discutir como tem ocorrido o ensino de matemática considerando a inclusão, implementou-se o presente estudo. Realizou-se uma pesquisa exploratória de cunho qualitativo, com a participação de 11 professores que atuam na rede básica de ensino do município de Boa Vista/RR. Os participantes desta pesquisa responderam a um questionário com intuito de identificar a formação pedagógica dos professores que atuam em turmas que possuem alunos com paralisia cerebral, especificamente em escolas de Educação Básica do município de Boa Vista/RR. Com base nas respostas obtidas, observou-se que os cursos de nível superior dos entrevistados, buscaram estar em conformidade com a recomendação da Portaria $\mathrm{n}^{\mathrm{o}} 1.793,16$ de dezembro de 1994, da inclusão de uma disciplina e conteúdos relacionados à Educação Especial, contudo não é suficiente para que se sintam preparados para desenvolver o fazer docente com os alunos com deficiência, sendo a formação continuada apontada como importante para que os professores atuem mais preparados no ensino da Matemática no contexto da educação inclusiva.
\end{abstract}

Palavras-chave: Formação de Professores; Inclusão escolar; Paralisia Cerebral.

\begin{abstract}
This article reflects on the teaching of Mathematics in the context of Inclusive Education. Studies that deal with the care of people with disabilities have advanced in recent years, bringing a better understanding of the ways of inclusion in school. Aiming to discuss how mathematics teaching has occurred considering inclusion, the present study was implemented. An exploratory qualitative research was carried out, with the participation of 11 teachers who work in the basic education network of the municipality of Boa Vista / RR. The participants of this research answered a questionnaire with the intention of identifying the pedagogical formation of the teachers who work in classes that have students with cerebral palsy, specifically in schools of Basic Education of the municipality of Boa Vista / RR. Based on the answers obtained, it was observed that the upper-level courses of the interviewees, sought to comply with the recommendation of Administrative Rule No. 1,793, December 16, 1994, of the inclusion of a discipline and contents related to Special Education, but not is enough to make them feel prepared to develop the teaching profession with students with disabilities, and continuing education is
\end{abstract}

\footnotetext{
${ }^{*}$ Mestre em Ensino de Ciências Exatas pela Universidade do Vale do Taquari - Univates. Professora no Instituto Federal de Educação, Ciência e Tecnologia de Roraima - IFRR, Roraima, Brasil. E-mail: lukaed45@gmasil.com ** Doutora em Ciências, Ecologia pela Universidade Federal do Rio Grande do Sul - UFRGS. Professora e pesquisadora na Universidade do Vale do Taquari - Univates, Lajeado, RS, Brasil. E-mail: aaguim@univates.br
} 
considered important for teachers to act more prepared in the teaching of Mathematics in the context of inclusive education.

Keywords/Palabras clave: Teacher training; School inclusion; Cerebral Palsy.

\section{Ensino de Matemática e a inclusão de pessoas com deficiência}

O presente artigo faz parte da dissertação de mestrado intitulada: O Jogo de Bocha adaptado como recurso no ensino da Matemática para alunos com Paralisia Cerebral, vinculada ao Programa de Pós-graduação Mestrado Profissional em Ensino de Ciências Exatas, pertencente ao Centro Universitário UNIVATES. Objetiva conhecer a formação pedagógica dos professores que atuam em turmas que possuem alunos com paralisia cerebral, especificamente em escolas de Educação Básica do município de Boa Vista/RR.

Considerando a abordagem teórica do tema inclusão e a efetivação da prática pedagógica ainda permanecem as dificuldades da atuação do professor relacionado às suas limitações do conhecimento, do saber e da atuação em sala de aula para com os escolares com deficiência (GREGUOL, GOBBI; CARRARO, 2013).

Os estudos que tratam sobre a atenção a Pessoas com Deficiência têm avançado, trazendo uma melhor compreensão das formas de inclusão na escola. Ao longo de décadas, a educação tem sofrido diversas transformações por meio de leis e práticas educacionais que representam o processo histórico, político e social de cada época. Isto tem ocorrido no intuito de aprimorar o sistema escolar brasileiro, no qual se vê a preocupação em adaptar as condições existentes à realidade da sociedade. Podemos citar, dessa forma, a educação voltada para pessoas com algum grau de deficiência, onde visualizamos o empenho de políticas públicas que possibilitam a essas pessoas o acesso ao ensino (CAMARGO, 2017).

Apesar das universidades estarem cumprindo a legislação que trata da inclusão de conteúdos relacionados a pessoas com deficiência nos cursos de licenciatura (BRASIL, 2000), há necessidade de melhorar a estruturação dos currículos e de práticas que garantam ao futuro docente se sentir preparado para lidar com o ensino de acordo com o universo de pessoas com deficiência.

Tão importante quanto regulamentar a Educação Inclusiva é executá-la. Por isso, a participação do professor se torna fundamental, pois ele é o mediador direto para tal execução, dotado de formação essencial para o funcionamento do sistema educacional. É dele que emanam os planejamentos e a criatividade para as aulas acontecerem (SILVA; REIS, 2011).

A formação docente apresenta desafios para atender e cumprir com as normas voltadas 
para preparação durante o cotidiano da vida acadêmica com base na matriz curricular dos cursos, de tal forma que o futuro docente possa desenvolver as suas aulas interagindo com Pessoas com Necessidades Educativas Especiais.

O professor é visto como possuidor de conhecimentos suficientes para instruir a sociedade, portanto considera-se a responsabilidade que esse profissional tem. Pensar na formação profissional implica em pensar na qualificação daqueles que são os executores diretos da educação brasileira (GREGUOL, GOBBI; CARRARO, 2013). Considera-se que o professor é o principal agente transformador, detendo a autonomia para incutir a inclusão e deve partir dele o compromisso para efetivação de uma educação de qualidade, "para tanto, são necessárias e imprescindíveis a colaboração e a participação do professor no processo inclusivo" (LIMA, 2010, p. 63).

É preciso considerar a habilidade, o querer e as condições didático-pedagógicas que o professor tem e/ou precisa desenvolver para uma educação de qualidade. É visível que de um lado se tem professores interessados em melhorar suas práticas e de um outro lado se tem a infraestrutura dos ambientes escolares que muitas vezes não lhes dá segurança para efetivação das aulas.

Considerando as deficiências é tamanha a necessidade da realização de trabalho interdisciplinar, principalmente para atingir os aspectos cognitivo, motor, afetivo e social dos alunos com deficiência. Fazenda (2008, p.17), ressalta que:

se definirmos Interdisciplinaridade como junção de disciplinas, cabe pensar currículo apenas na formatação de sua grade. Porém, se definirmos Interdisciplinaridade como atitude de ousadia e busca frente ao conhecimento, cabe pensar aspectos que envolvem a cultura do lugar onde se formam professores.

Diante da exposição de interdisciplinaridade apresentada por Fazenda (2008), é preciso que no âmbito da formação de professores haja o pensamento voltado para atitude, ousadia e busca que excede o pensamento fechado sobre a formação do currículo. Visto que não é suficiente dizer que 'o acadêmico em formação tem a preparação devida, tanto teórico com prático, para a utilização da metodologia interdisciplinar', se não há vivência desta, mesmo que se tenham disciplinas voltadas para a inclusão, o processo fica fragilizado.

\section{Caminhos percorridos na investigação}

Utilizou-se neste estudo abordagem qualitativa, que trata da investigação de valores, atitudes, percepções e motivações do público pesquisado com o objetivo principal de compreendê-los em profundidade e esta, não tem preocupação estatística. Caracterizou-se como 
uma pesquisa de campo, onde a pesquisadora foi até o espaço escolar, onde o processo de ensino investigado ocorre a fim de reunir informações (GONÇALVES; MEIRELLES, 2004).

Trata-se de pesquisa aplicada, de natureza descritiva e exploratória que se deu em relação à investigação sobre a formação dos professores de Matemática, Educação Física, professores Auxiliares e professores da sala de Recurso Multifuncional, especificamente, quanto à preparação técnica e pedagógica destes para a educação inclusiva. Estes professores foram convidados para participar desta pesquisa, pois foram desenvolvidas atividades relacionadas a conteúdos de matemática e educação física com os alunos deficientes inclusos em suas turmas. Aqui neste estudo apresenta-se apenas um recorte contendo as percepções e concepções dos professores.

Através de sondagem realizada junto a 60 escolas da Rede Pública de Ensino em Boa Vista/RR, foi possível identificar o universo desse estudo que consiste em: três (03) professores de Matemática, três (03) professores de Educação Física, três (02) professores Auxiliares e três (03) professores da sala de Recurso Multifuncional de três escolas da Rede Estadual de Ensino, que possuem em uma de suas classes um aluno com paralisia cerebral.

Os professores foram inicialmente convidados, momento onde ocorreu a exposição da proposta e posteriormente aqueles que aceitaram, assinaram o Termo de Consentimento Livre e Esclarecido, concordando em participar do processo. Foi posteriormente realizado um encontro onde aplicou-se um questionário composto por questões mistas que foram respondidos individualmente. Objetivou-se nesta etapa da pesquisa verificar a formação dos professores especificamente quanto à preparação técnica e pedagógica para a educação inclusiva suas concepções percepções sobre o processo de ensino e de aprendizagem dos alunos com deficiência. Para analisar os dados obtidos optou-se por Análise de Conteúdo (BARDIN, 2011).

As questões respondidas pelos professores versavam sobre a ocorrência de disciplinas relacionadas à Educação Especial durante a sua formação docente; sobre a participação em cursos de capacitação e/ou especialização para atuar na área de Educação Especial e no atendimento de pessoas com Deficiência Física; sobre as percepções do docente considerando a formação recebida durante a realização do seu curso de licenciatura e a relação desta com a sua prática pedagógica diária; sobre os incentivos recebidos do governo para atuar na área de Educação especial; sobre as dificuldades enfrentadas diariamente pelo docente em sua rotina em sala de aula; além de problematizar quais as estratégias devem ser implementadas para que ocorra efetivamente a inclusão de alunos com deficiência física nas escolas do município em estudo. 


\section{Resultados e discussão}

Durante a apresentação inicial da proposta de pesquisa aos professores foi verificada a falta de conhecimento sobre os tipos de deficiência, as diferenças sobre deficiência física e intelectual, principalmente no tocante à Paralisia Cerebral. Os professores pensavam inicialmente que os alunos eram deficientes intelectuais pelo fato de estarem em cadeira de rodas e não conseguirem se comunicarem com facilidade.

Diante desse cenário, foi necessário que a pesquisadora desenvolvesse com o grupo de participantes da pesquisa uma roda de conversa para discutir os tipos de deficiências, suas caraterísticas e classificações. Este momento de discussão buscou fomentar a reflexão sobre o tema deficiência e inclusão, para que os professores entendessem as dificuldades de seus alunos com deficiência através de suas características, compreendendo que independente de suas limitações é preciso tornar possível o ensino para os alunos com Paralisia Cerebral. Buscando novos recursos e estratégias de ensino para que ocorra a aprendizagem efetiva dos conteúdos trabalhados em sala de aula.

Após o momento de problematização inicial, os professores participantes da presente pesquisa responderam ao questionário que posteriormente foi analisado. Perguntou-se sobre a participação de disciplinas relacionadas à Educação Especial durante a sua formação acadêmica e observou-se que apenas o professor de matemática da escola "A" não teve nenhuma disciplina dentre os onze (11) entrevistados.

Dez (10) participantes informaram que durante a sua formação acadêmica tiveram disciplinas relacionadas à Educação Especial, desta forma verificamos que as universidades nas quais os entrevistados estudaram, buscaram estar em conformidade com Brasil (1994) relativo à Portaria $\mathrm{n}^{\mathrm{o}}$ 1.793, 16 de dezembro de 1994, que recomenda a inclusão de uma disciplina e conteúdos relacionados à Educação Especial principalmente aos cursos de licenciatura, demonstrando uma mudança significativa relacionada ao currículo, atendendo assim as demandas atuais existentes na área educacional.

Observamos que oito (08) professores responderam que participaram de cursos de capacitação relacionados à Educação Especial durante o período de formação acadêmica e apenas três (03) responderam que não. Estas informações podem ser observadas no quadro 1. 
Quadro 01: Representação da Capacitação dos docentes durante a Formação

\begin{tabular}{|c|c|c|c|}
\hline $\begin{array}{l}\text { Participou de capacitação na área da Educação } \\
\text { Especial? }\end{array}$ & Sim & Não & Quais \\
\hline Professor de Matemática da Escola "A" & $\mathrm{X}$ & & $\begin{array}{l}\checkmark \text { Disciplinas da pós- } \\
\text { graduação }\end{array}$ \\
\hline Professor de Matemática da Escola "B" & $\mathrm{X}$ & & $\checkmark$ Não lembra \\
\hline Professor de Matemática da Escola “C" & & $\mathrm{X}$ & \\
\hline Professor de Educação Física da Escola "A" & $\mathrm{X}$ & & $\begin{array}{|ll|}\checkmark & \text { Libras; } \\
\checkmark & \text { Atendimento Educacional } \\
& \text { Especializado (AEE) } \\
\end{array}$ \\
\hline Professor de Educação Física da Escola "B" & $\mathrm{X}$ & & \begin{tabular}{|ll}
$\checkmark$ & Educação Física adaptada; \\
$\checkmark$ & Educação Inclusiva; \\
$\checkmark$ & Atividades recreativas adaptadas
\end{tabular} \\
\hline Professor de Educação Física da Escola "C" & & $\mathrm{X}$ & \\
\hline $\begin{array}{l}\text { Professor da Sala de Recurso Multifuncional } \\
\text { da Escola "A" }\end{array}$ & $\mathrm{X}$ & & $\begin{array}{lll}\checkmark & \text { Atendimento Educacional } \\
& \text { Especializado (AEE); } \\
\checkmark & \text { Alfabetização do Deficiente } \\
\text { Intelectual. } & \end{array}$ \\
\hline $\begin{array}{l}\text { Professor da Sala de Recurso Multifuncional } \\
\text { da Escola "B" }\end{array}$ & $\mathrm{X}$ & & \begin{tabular}{|ll}
$\checkmark$ & Libras; \\
$\checkmark$ & Deficiência Intelectual.
\end{tabular} \\
\hline $\begin{array}{l}\text { Professor da Sala de Recurso Multifuncional } \\
\text { da Escola "C" }\end{array}$ & $\mathrm{X}$ & & $\checkmark \quad \mathrm{DM}$ \\
\hline Professor Auxiliar da Escola "A" & & $\mathrm{X}$ & \\
\hline Professor Auxiliar da Escola "B" & $\mathrm{X}$ & & $\checkmark$ Libras \\
\hline TOTAL: & 8 & 3 & \\
\hline
\end{tabular}

Verificamos que dois (02) dos que responderam sim, durante a sua formação só participaram de um curso de capacitação voltado para área de Educação Especial: Libras e Deficiência Mental (DM). Três (03) professores fizeram dois cursos: Libras, Atendimento Educacional Especializado (AEE), Deficiência Intelectual e Alfabetização do Deficiente Intelectual. Apenas um (01) professor participou durante a sua formação de três cursos de capacitação que foram: Educação Física adaptada, Educação Inclusiva e Atividades recreativas adaptadas. Um (01) dos professores informou que participou, mas não recordava o nome do curso e um (01) relatou sobre as disciplinas no curso de especialização, ou seja, este considerou como curso de capacitação as disciplinas ministradas no curso de especialização. Os cursos de Libras e Atendimento Educacional Especializado e cursos relacionados à Deficiência Intelectual foram os mais cursados.

Sabe-se da importância da qualificação de professores para o desempenho de seu papel com qualidade frente à diversidade, pois garante conhecimentos necessários para o desenvolvimento de habilidades pelos alunos de forma segura (CASTANHO; FREITAS, 2005).

Verificamos que seis (06) professores não possuem especialização voltada para Educação Especial, enquanto três (03) possuem a referida especialização e dois (02) estão 
cursando. Ao analisarmos as respostas, observamos que dos que possuem especialização com os que estão cursando, temos uma projeção de $45 \%$ dos professores participantes da pesquisa, totalizando cinco (05), desta maneira percebemos um aumento no interesse pelo conhecimento na área da Educação Especial.

Perguntamos sobre a existência de incentivos relacionados à melhoria das condições de ensino para os professores que atuam na rede pública e que trabalham com alunos com deficiência em sala de aula. As respostas e os incentivos recebidos por alguns docentes encontram-se no quadro a seguir (Quadro 2).

Quadro 2: Incentivos recebidos pelos docentes

\begin{tabular}{|c|c|c|c|}
\hline & $\begin{array}{l}\text { Recebeu } \\
\text { Incentivo }\end{array}$ & $\begin{array}{l}\text { Não } \\
\text { Recebeu } \\
\text { Incentivo } \\
\end{array}$ & Quais \\
\hline Professor de Matemática da Escola "A" & & $\mathrm{X}$ & \\
\hline Professor de Matemática da Escola "B" & & $\mathrm{X}$ & \\
\hline Professor de Matemática da Escola "C" & $\mathrm{X}$ & & $\sqrt{ }$ Cursos de capacitação. \\
\hline Professor de Educação Física da Escola "A" & & $\mathrm{X}$ & \\
\hline Professor de Educação Física da Escola "B" & $\mathrm{X}$ & & $\checkmark$ Cursos de capacitação \\
\hline Professor de Educação Física da Escola "C" & & $\mathrm{X}$ & \\
\hline $\begin{array}{l}\text { Professor da Sala de Recurso Multifuncional } \\
\text { da Escola "A" }\end{array}$ & $\mathrm{X}$ & & $\begin{array}{l}\checkmark \text { Material pedagógico; } \\
\checkmark \text { Cursos de capacitação. }\end{array}$ \\
\hline $\begin{array}{l}\text { Professor da Sala de Recurso Multifuncional } \\
\text { da Escola "B" }\end{array}$ & $\mathrm{X}$ & & $\begin{array}{l}\checkmark \text { Materiais Pedagógicos; } \\
\checkmark \text { Curso de capacitação. }\end{array}$ \\
\hline $\begin{array}{l}\text { Professor da Sala de Recurso Multifuncional } \\
\text { da Escola "C" }\end{array}$ & $\mathrm{X}$ & & $\sqrt{ }$ Recursos pedagógicos \\
\hline Professor Auxiliar da Escola "A" & & $\mathrm{X}$ & \\
\hline Professor Auxiliar da Escola "B" & & $\mathrm{X}$ & \\
\hline TOTAL: & 5 & 6 & \\
\hline
\end{tabular}

A respeito da existência de incentivo, verificamos que seis (06) professores não se sentem contemplados e não reconhecem ações para melhoria das condições de ensino para alunos inclusos. Por outro lado, cinco (05) dos entrevistados informaram que receberam incentivos como professores da Rede Pública para o atendimento do aluno com Deficiência. Dentre os cinco (05) que receberam incentivos, quatro (04) relataram que lhes foi proporcionado cursos de capacitação e apenas dois (02) receberam recursos pedagógicos.

Percebemos aqui duas realidades que nos levam a refletir sobre o papel da rede pública de ensino e o nosso papel como professores dessa rede. Verificamos que uma boa parte dos professores recebeu incentivo. Dessa forma, podemos levar em consideração duas hipóteses: todas as escolas receberam o mesmo incentivo e os professores não tiveram interesse em verificar ou participar, ou a rede pública encaminhou recursos para algumas escolas e outras 
não. De acordo com Ferreira (2005, p.2), "ter acesso à escola, lá permanecer, mas na sala de aula, ficar [em] excluídos [s] dos processos de ensino-aprendizagem" parece ser algo bem real na atualidade. Marin (2005, p.36) relata que "a figura central da atividade de ensinar é a figura do professor. O trabalho docente se configura, portanto, como o trabalho executado pelo professor para dar conta do ensino" - este como "parcela da educação escolarizada, está sujeito à organização do trabalho nas unidades escolares, como as normas e recursos provenientes do sistema escolar, bem como está sujeito a limitações, exigências e possibilidades permitidas pelo sistema social mais amplo" (MARIN, 2005, p. 37).

De acordo com Schloss apud (STAINBACK; STAINBACK 1999, p. 25), os professores "precisam adquirir novas habilidades para trabalhar com alunos acadêmica e socialmente deficientes". A capacitação é um dos caminhos para que haja uma melhoria do ensino, não só para alunos com deficiência, mas para todos os alunos.

Em relação à capacitação voltada para o atendimento da pessoa com deficiência física, podemos perceber no quadro três que sete (07) professores responderam que não possuem capacitação específica.

Quadro 3: Curso ou capacitação voltada para o atendimento das pessoas com Deficiência Física realizado pelos docentes

\begin{tabular}{|c|c|c|c|}
\hline & Sim & Não & Quais \\
\hline Professor de Matemática da Escola "A" & & $\mathrm{X}$ & \\
\hline Professor de Matemática da Escola "B" & & $\mathrm{X}$ & \\
\hline Professor de Matemática da Escola “C" & & $\mathrm{X}$ & \\
\hline Professor de Educação Física da Escola "A" & & $\mathrm{X}$ & \\
\hline Professor de Educação Física da Escola "B" & & $\mathrm{X}$ & \\
\hline Professor de Educação Física da Escola "C" & & $\mathrm{X}$ & \\
\hline $\begin{array}{l}\text { Professor da Sala de Recurso Multifuncional da } \\
\text { Escola "A" }\end{array}$ & $\mathrm{X}$ & & $\begin{array}{ll}\checkmark \text { Atendimento } & \text { Educacional } \\
\text { Especializado (AEE) } & \\
\end{array}$ \\
\hline $\begin{array}{l}\text { Professor da Sala de Recurso Multifuncional da } \\
\text { Escola "B" }\end{array}$ & $\mathrm{X}$ & & $\begin{array}{l}\checkmark \text { Deficiência Física; } \\
\checkmark \text { Paralisia Cerebral. }\end{array}$ \\
\hline $\begin{array}{l}\text { Professor da Sala de Recurso Multifuncional da } \\
\text { Escola "C", }\end{array}$ & $\mathrm{X}$ & & $\begin{array}{l}\checkmark \text { Capacitação para Sala de Recursos } \\
\text { Multifuncionais. }\end{array}$ \\
\hline Professor Auxiliar da Escola "A" & & $\mathrm{X}$ & \\
\hline Professor Auxiliar da Escola "B" & $\mathrm{X}$ & & $\checkmark$ Confecção de Material adaptado \\
\hline TOTAL: & 04 & 07 & \\
\hline
\end{tabular}

Apenas quatro (04) professores responderam que possuem a capacitação específica para o atendimento da Pessoa com Deficiência Física. Destes, três são professores da sala de recursos multifuncionais e um professor auxiliar. A Resolução CNE/CEB nº 2/2001, também aborda sobre a formação dos professores de classe comum. Recomenda que, para atendimento dos 
alunos relacionados às suas necessidades educacionais, é mister que os professores sejam capacitados e comprovem que, na sua formação, seja ela no ensino superior ou no ensino médio, houve a inclusão de conteúdos sobre educação especial, adequados ao desenvolvimento de valores e competências para:

I - perceber as necessidades educacionais especiais dos alunos e valorizar a educação inclusiva; II - flexibilizar a ação pedagógica nas diferentes áreas de conheci mento de modo adequado às necessidades especiais de aprendizagem;

III - avaliar continuamente a eficácia do processo educativo para o atendimento de necessidades educacionais especiais;

IV - atuar em equipe, inclusive com professores especializados em educação especial (BRASIL, 2001, p. 5).

Buscamos identificar a visão dos professores sobre a importância da formação direcionada ao atendimento da pessoa com deficiência Física para a sua prática pedagógica diária, observamos que os onze (11) responderam que veem essa formação como importante.

Para Ferreira (2005, p. 13):

a maioria dos professores da educação especial tem pouca formação que os habilite a contribuir com o trabalho pedagógico desenvolvido no ensino comum, uma vez que eles têm se especializado de forma apartada da educação comum e centrada nas intervenções que minimizam os impactos gerados no desenvolvimento pelas especificidades da cegueira, da surdez, da deficiência física ou mental.

Referente às melhorias necessárias para a inclusão dos alunos com Deficiência Física, os professores apontaram mais de uma opção, pois veem todos os itens que constam no questionário como imprescindíveis para que o atendimento do aluno com deficiência física seja realmente efetivo. Contudo, não levantaram outros pontos além dos questionados, como podemos verificar a seguir no quadro (4).

Quadro 4: Melhorias necessárias para a inclusão dos alunos com Deficiência Física nas aulas

\begin{tabular}{|l|ll|}
\hline & & \multicolumn{1}{c|}{ Quais } \\
\hline Professor de Matemática da Escola "A" & $\checkmark$ & Espaço físico; \\
& $\checkmark$ & Material pedagógico; \\
& $\checkmark$ & Capacitação profissional; \\
& $\checkmark$ & Mais apoio da gestão; \\
& $\checkmark$ & Participação de pais; \\
& $\checkmark$ & Participação da comunidade. \\
\hline Professor de Matemática da Escola "B" & $\checkmark$ & Formação \\
\hline
\end{tabular}




\begin{tabular}{|c|c|c|}
\hline Professor de Matemática da Escola "C" & & $\begin{array}{l}\text { Apoio da gestão; } \\
\text { Material pedagógico }\end{array}$ \\
\hline Professor de Educação Física da Escola "A" & $\begin{array}{l}\checkmark \\
\checkmark \\
\checkmark \\
\checkmark \\
\checkmark \\
\checkmark\end{array}$ & $\begin{array}{l}\text { Infraestrutura da escola; } \\
\text { Espaço físico; } \\
\text { Acessibilidade; } \\
\text { Materiais pedagógicos; } \\
\text { Relações interpessoais; } \\
\text { Apoio da coordenação pedagógica }\end{array}$ \\
\hline Professor de Educação Física da Escola "B" & & $\begin{array}{l}\text { Espaço físico; } \\
\text { Apoio pedagógico; } \\
\text { Capacitação profissional; } \\
\text { Recursos materiais }\end{array}$ \\
\hline Professor de Educação Física da Escola "C" & & $\begin{array}{l}\text { Material pedagógico; } \\
\text { Adaptações na quadra; } \\
\text { Materiais adaptados específicos para tal aluno }\end{array}$ \\
\hline $\begin{array}{l}\text { Professor da Sala de Recurso Multifuncional } \\
\text { da Escola "A" }\end{array}$ & $\checkmark$ & $\begin{array}{l}\text { Compreensão da comunidade escolar sobre a inclusão } \\
\text { escolar como direito, não só legislativo, mas como ser } \\
\text { humano que merece respeito. }\end{array}$ \\
\hline $\begin{array}{l}\text { Professor da Sala de Recurso Multifuncional } \\
\text { da Escola "B" }\end{array}$ & $\begin{array}{l} \\
\checkmark \\
\checkmark\end{array}$ & $\begin{array}{l}\text { Acessibilidade; } \\
\text { Recursos pedagógicos. }\end{array}$ \\
\hline $\begin{array}{l}\text { Professor da Sala de Recurso Multifuncional } \\
\text { da Escola "C" }\end{array}$ & $\begin{array}{l}\checkmark \\
\checkmark\end{array}$ & $\begin{array}{l}\text { Receber esse aluno com carinho; } \\
\text { Dar apoio, receber a família e receber o aluno. }\end{array}$ \\
\hline Professor Auxiliar da Escola "A" & & $\begin{array}{l}\text { Espaço físico; } \\
\text { Material pedagógico; } \\
\text { Capacitação profissional; } \\
\text { Apoio da gestão; } \\
\text { Participação dos pais }\end{array}$ \\
\hline Professor Auxiliar da Escola "B" & $\begin{array}{l}\checkmark \\
\checkmark \\
\checkmark\end{array}$ & $\begin{array}{l}\text { O material pedagógico; } \\
\text { A relação dessa parceria no planejamento; } \\
\text { Capacitação. }\end{array}$ \\
\hline
\end{tabular}

Tendo em vista um dos itens citados pelos professores, que é a capacitação profissional, consta no texto da Política Nacional de Educação na Perspectiva da Educação Inclusiva (PNEEPEI) que "para atuar na Educação Especial, o professor deve ter como base da sua formação, inicial e continuada, conhecimentos gerais para o exercício da docência e conhecimentos específicos da área" (BRASIL, 2008, p. 17). Uma das ações realizadas pelo Ministério da Educação (MEC) é o programa Educação Inclusiva: direito à diversidade. Este tem por objetivo central a promoção da:

Formação de gestores e educadores para efetivar a transformação dos sistemas educacionais inclusivos, tendo como princípio a garantia do direito dos alunos com necessidades educacionais especiais de acesso e permanência, com qualidade, nas escolas regulares (BRASIL, 2005, p.9).

Além dessa formação o Programa Educação Inclusiva: Direito à Diversidade:

disponibilizará, para os municípios-pólo e secretarias estaduais de educação equipamentos, mobiliário e materiais pedagógicos, para a implantação da sala de recursos multifuncionais destinadas ao atendimento educacional especializado, com vista a apoiar o processo de inclusão educacional dos alunos com necessidades 
educacionais especiais na rede pública de ensino (BRASIL, 2005, p.9).

Percebemos que nas escolas que fizeram parte desta pesquisa, as ações acontecem, mas existe a necessidade de melhorias relacionadas aos recursos e materiais pedagógicos para serem utilizados tanto pelo professor da sala de recursos quanto pelos professores das classes comuns. Verificamos, posteriormente através do questionário, a veracidade do fato relatado no início da discussão dos resultados, ao questionarmos sobre o tipo de deficiência física que seus respectivos alunos tinham como podemos ver no quadro (5).

Quadro 5: Tipo de Deficiência física apresentada pelos alunos com os quais os docentes atuam

\begin{tabular}{|l|l|}
\hline & \multicolumn{1}{|c|}{ Tipo de deficiência física } \\
\hline Professor de Matemática da Escola "A" & $\checkmark$ Interativo; \\
& $\checkmark$ Deficiente mais alongada; \\
& $\checkmark$ Algum tipo de mobilidade; \\
& $\checkmark$ Deficiência em termo de aprendizagem \\
\hline Professor de Matemática da Escola "B" & $\checkmark$ Cadeirante \\
\hline Professor de Matemática da Escola "C" & $\checkmark$ Um deficiente físico - cadeirante; \\
& $\checkmark$ Um de uma perna só \\
\hline $\begin{array}{l}\text { Professor de Educação Física da Escola } \\
\text { "A" }\end{array}$ & $\checkmark$ Paralisia cerebral \\
\hline $\begin{array}{l}\text { Professor de Educação Física da Escola } \\
\text { "B" }\end{array}$ & $\checkmark$ Autista \\
\hline $\begin{array}{l}\text { Professor de Educação Física da Escola } \\
\text { "C" }\end{array}$ & $\checkmark$ Paralisia cerebral \\
\hline $\begin{array}{l}\text { Professor da Sala de Recurso } \\
\text { Multifuncional da Escola "A" }\end{array}$ & $\checkmark$ Dois com Paralisia cerebral; \\
\hline $\begin{array}{l}\text { Professor da Sala de Recurso } \\
\text { Multifuncional da Escola "B" }\end{array}$ & $\checkmark$ Um a deficiência física e intelectual; \\
\hline $\begin{array}{l}\text { Professor da Sala de Recurso } \\
\text { Multifuncional da Escola "C" }\end{array}$ & $\checkmark$ Um com paralisia cerebral; \\
\hline Professor Auxiliar da Escola "A" & $\checkmark$ Dois com deficiências múltiplas \\
\hline Professor Auxiliar da Escola "B" & $\checkmark$ Deficiência Mental e tem deficiências físicas também. \\
\hline
\end{tabular}

Observamos a partir do quadro 5, que alguns professores não têm o conhecimento específico sobre tipos de Deficiência Física, a exemplo de alguns que não conhecem os termos técnicos utilizados e suas características. Percebemos também que a escola não possui o laudo médico dos alunos para que os professores tomem conhecimento do tipo de deficiência que o aluno tem. Segue as informações de alguns professores:

Professor Auxiliar da escola "A" - Deficiência Mental e tem deficiências físicas também. Na verdade nós não temos um laudo trazido pela família, até hoje. Apesar dela ser aluna da escola a 3, 4 anos não temos um laudo dizendo na verdade qual a deficiência. 
Professor de Matemática da escola "B”: Olha, ele é cadeirante né? Ele não se locomove sozinho.

Professor de Matemática da escola "C”: O aluno, ele tem a deficiência fisica, ele é cadeirante, e ele é também tem deficiência mental e a aluna é deficiente de uma perna só, deficiente fisica né?

Professor de Matemática da escola “A”: Cada um na sua necessidade tem um que é mais interativo, tem outro que já é uma deficiência mais alongada, algum tipo de mobilidade, outros com deficiência mais em termo de aprendizagem, uma deficiência bem complicada, porque a gente tem que ter muito cuidado com relação a uma abordagem dos conteúdos porque ele ainda é um pouco mais lento em relação aos outros alunos, mais eles têm certa compilação dos conteúdos, porém não tão na velocidade que a gente costuma observar nos demais alunos.

Para obter mais informações acerca do aluno da escola "B" a professora informou que: Professor Auxiliar da escola " $B$ " - fui à casa da mãe dele conversar e nós conseguimos aquele laudo daquela viajem que ele fez pra Brasília que ele fez tratamento que foi interrompido e devido essa interrupção, foi que eu fui conhecer o que aconteceu com a interrupção da viajem do tratamento que causou essa situação dele, porque ate então ele tinha alguns movimentos. Fez a cirurgia e o que está escrito no laudo é Paralisia Cerebral Espástica.

A realidade dos professores entrevistados nessa pesquisa é que a grande maioria tem dificuldades em planejar suas aulas para o aluno com deficiência física. Podemos confirmar essa informação no quadro (6), no qual verificamos que sete (07) professores informaram que sentem dificuldade em planejar tendo o aluno com Deficiência Física em suas aulas, dois (02) professores sentem dificuldades às vezes e apenas dois (02) informaram na entrevista que não sentem nenhuma dificuldade em planejar suas aulas para turmas que tenham alunos com Deficiência Física. 
Quadro 6: Dificuldade no planejamento das aulas, considerando a inclusão de um aluno com Deficiência Física

\begin{tabular}{|c|c|c|c|}
\hline & Sim & Não & Quais \\
\hline $\begin{array}{l}\text { Professor de Matemática da Escola } \\
\text { "A" }\end{array}$ & $\mathrm{X}$ & & $\begin{array}{l}\checkmark \text { Trabalhar de forma lúdica assuntos que } \\
\text { teoricamente são mais complicados e } \\
\text { desafiadores; } \\
\checkmark \text { Tirar a abstração que a matemática tem muitas } \\
\text { vezes e torna-lo o máximo possível, em uma } \\
\text { coisa mais visual. }\end{array}$ \\
\hline $\begin{array}{l}\text { Professor de Matemática da Escola } \\
\text { "B" }\end{array}$ & $\mathrm{X}$ & & $\begin{array}{l}\checkmark \text { Por não ter formação específica na área da } \\
\text { educação especial }\end{array}$ \\
\hline $\begin{array}{l}\text { Professor de Matemática da Escola } \\
\text { "C" }\end{array}$ & $\mathrm{X}$ & & $\begin{array}{l}\checkmark \text { Os conteúdos são diferentes mas não relatou } \\
\text { quais as dificuldades }\end{array}$ \\
\hline $\begin{array}{l}\text { Professor de Educação Física da } \\
\text { Escola "A" }\end{array}$ & $\mathrm{X}$ & & $\begin{array}{l}\checkmark \text { Pela falta de participação da aluna; } \\
\checkmark \text { Eu não sei que atividades que eu poderia tá } \\
\text { colocando pra que toda a turma participasse; }\end{array}$ \\
\hline $\begin{array}{l}\text { Professor de Educação Física da } \\
\text { Escola "B" }\end{array}$ & $\mathrm{X}$ & & $\begin{array}{l}\checkmark \text { A resistência da turma; } \\
\checkmark \text { O espaço físico (quadra) }\end{array}$ \\
\hline $\begin{array}{l}\text { Professor de Educação Física da } \\
\text { Escola "C" }\end{array}$ & $\mathrm{X}$ & & $\begin{array}{l}\checkmark \text { Planejar atingindo toda a turma incluindo esse } \\
\text { aluno. }\end{array}$ \\
\hline $\begin{array}{l}\text { Professor da Sala de Recurso } \\
\text { Multifuncional da Escola "A" }\end{array}$ & & $\mathrm{X}$ & \\
\hline $\begin{array}{l}\text { Professor da Sala de Recurso } \\
\text { Multifuncional da Escola "B" }\end{array}$ & Às vezes & & $\checkmark$ Por não ter um recurso adequado \\
\hline $\begin{array}{l}\text { Professor da Sala de Recurso } \\
\text { Multifuncional da Escola "C" }\end{array}$ & Às vezes & & $\begin{array}{l}\checkmark \text { Por ser deficiente físico é mais complicado o } \\
\text { planejamento }\end{array}$ \\
\hline Professor Auxiliar da Escola "A" & $\mathrm{X}$ & & $\begin{array}{l}\checkmark \text { Falta de planejamento com o professor das } \\
\text { disciplinas }\end{array}$ \\
\hline Professor Auxiliar da Escola "B" & & $\mathrm{X}$ & $\begin{array}{l}\checkmark \text { Falta de Planejamento com o professor da } \\
\text { disciplina }\end{array}$ \\
\hline TOTAL: & 07 & 02 & $02-$ Às vezes \\
\hline
\end{tabular}

De acordo com Ostetto (2000) planejar é:

essa atitude de traçar, projetar, programar, elaborar um roteiro para empreender uma viagem de conhecimento, de interação, de experiências múltiplas e significativas para/com o grupo de crianças. Planejamento pedagógico é atitude crítica do educador diante de seu trabalho docente. Por isso não é uma forma! Ao contrário, é flexível e, como tal, permite ao educador repensar, revisando, buscando novos significados para sua prática pedagógica (OSTETTO, 2000, p.177).

Muitas vezes a falta de conhecimento sobre o tipo de deficiência, suas características e o trabalho interdisciplinar, acaba dificultando o planejamento, pois infelizmente algumas pessoas ainda enxergam as pessoas com deficiência por suas limitações, esquecendo-se de verificar quais são suas potencialidades, para que a partir daí possam planejar suas aulas com intuito de que verdadeiramente possam ter indícios de aprendizagens na vida desses alunos. 


\section{Considerações finais}

Este artigo contribui para uma reflexão sobre a importância do conhecimento teórico e prático na formação inicial do docente, para o desenvolvimento da vida escolar do aluno com deficiência. Os resultados indicam que os estudos nos cursos de nível superior dos quais os entrevistados estudaram, buscaram a inclusão de uma disciplina e conteúdos relacionados à Educação Especial. Contudo, não é suficiente para que os acadêmicos na sua futura atuação como professores se sintam preparado para desenvolver o fazer docente com os alunos com deficiência, há necessidade de melhor qualificação para que a inclusão seja real, haja vista que não basta apenas às universidades fazerem sua parte, mas a continuidade da formação pedagógica dos professores deve ser parte de seu cotidiano para que haja uma mudança na realidade do ensino para as Pessoas com Deficiência.

Quanto mais o professor se adéqua à realidade dos alunos, melhor será a qualidade de ensino e consequentemente a inclusão estará mais perto de ser efetivada. Entretanto a maioria dos professores possui cursos voltados para o atendimento da Pessoa com Deficiência de forma geral, e os cursos específicos foram direcionados aos professores das salas de recurso multifuncional, a exemplo do curso intitulado Atendimento Educacional Especializado, que obteve conhecimento, estando solicitado para atendimento da escola como todo.

Durante a pesquisa por diversas vezes os professores demonstraram estar confusos sobre a identificação do tipo da Deficiência Física, que seu aluno tem. Com isso, verifica-se a necessidade de aperfeiçoamento com relação à formação pedagógica dos professores que atuam em turmas que possuem alunos com paralisia cerebral, especificamente em escolas de Educação Básica do município de Boa Vista/RR.

Observou-se a falta de interesse de alguns profissionais em querer conhecer seus alunos, fazer um diagnóstico da turma e dos alunos que nela se encontram, poderia ser um caminho para melhoria do ensino, e complementação das lacunas do ensino superior, pois ao conhecer a realidade sobre o meio em que trabalhamos, possibilita planejar com vistas à inclusão.

A formação inicial precisa ser repensada pelos professores formadores em parceria com os órgãos responsáveis pela inclusão para sistematizar a qualificação especifica nessa área dos já, e futuros docentes, por meio da valorização profissional e melhoria da estruturação escolar para uma educação de qualidade, que requer também a nossa responsabilidade enquanto profissionais no cumprimento do nosso papel e função de ser professor com escolares com deficiência, essa responsabilidade é fundamentada naquilo que acreditamos que seja possível 
realizar no âmbito escolar por meio da educação formal, tenho certeza que cumpriremos com o nosso papel docente com excelência através da busca incessante da formação continuada. Por isso, é preciso conhecer o docente que irá atuar no contexto da inclusão desde a sua formação profissional, qual o seu interesse em possibilitar práticas interdisciplinares para que os alunos sejam incluídos, pois o querer trabalhar com as deficiências surge ou são aflorados no nível superior, sendo relevante para a efetivação do ensino e da aprendizagem, não só conteudista, mas significativa, dos alunos com deficiência. Ainda assim é importante a continuidade de estudos, por meio de programas de capacitação, generalizados sobre os tipos de deficiência, dado ao fato de inclusão nas escolas.

\section{Referências}

BARDIN, L. (2011). Análise de conteúdo. São Paulo: Edições 70.

BRASIL (1994). Ministério da Educação. Portaria ${ }^{\circ} 1.793$, de dezembro de 1994. Disponível em: <http://portal.mec.gov.br/seesp/arquivos/pdf/port1793.pdf>. Acesso em: 24 mai. 2012.

BRASIL (2000). Conselho Nacional de Educação. Proposta de Diretrizes para a formação inicial de professores da educação básica, em cursos de nível superior. Brasília.

BRASIL (2001). Conselho Nacional de Educação. Câmara de Educação Básica. Resolução no 2, de 11 de setembro de 2001. Diretrizes nacionais para a educação especial na educação básica. Brasília.

BRASIL (2005). Ministério da Educação. Programa de educação inclusiva: direito à diversidade. Documento orientador. Brasília, DF: MEC.

BRASIL (2008). Ministério da Educação. Política nacional de educação especial na perspectiva da educação inclusiva. Brasília, DF: MEC.

CAMARGO, E. P. de. (2017). Inclusão social, educação inclusiva e educação especial: enlaces e desenlaces. Ciênc. educ. (Bauru), Bauru, v. 23, n. 1, p. 1-6.

CASTANHO, D. M.; FREITAS, S. N. (2005). Inclusão e prática docente no ensino superior. Centro de Educação. Revista Brasileira de Educação Especial, Santa Maria, RS, caderno 2005, n. 27. Disponível em: http://coralx.ufsm.br/revce/ceesp/2006/01/r6.htm. Acesso em: 07 jan. 2014.

FAZENDA, I. C. A (2008). O que é interdisciplinaridade? São Paulo: Cortez.

FERREIRA, M. C. C. (2005). Alunos com deficiência na escola comum: os professores ensinam? Eles aprendem? Anais...28 reunião anual da Anped, Caxambu.

GONÇALVES, C. A.; MEIRELlES, A. M. (2004). Projetos e Relatórios de Pesquisa em Administração. São Paulo: Atlas. 
GREGUOL, M.; GOBBI, E.; CARRARO, A. (2013). Formação de professores para a educação especial: uma discussão sobre os modelos brasileiro e italiano. Rev. bras. educ. espec., Marília, v. 19, n. 3 , p. 307-324.

LIMA, P. A. (2010). Educação inclusiva: indagações e ações nas áreas de educação e da saúde. São Paulo: Avercamp.

MARIN, A. J. (2005). O trabalho docente: núcleo de perspectiva globalizadora de estudos sobre ensino. In: Marin, A. J. (Coord.). Didática e trabalho docente. 2. ed. Araraquara, SP: p. 30-65.

OSTETTO, L. E. (2000). Planejamento na educação infantil: mais que a atividade, a criança em foco. In: Ostetto, L. (Org.). Encontros e encantamentos na educação infantil: partilhando experiências de estágios. Campinas: Papirus, p.175-199.

SILVA, L. R. de S.; REIS, M. B. de F. (2011). Educação inclusiva: o desafio da formação de professores. Revelli. Revista de Educação, Linguagem e Literatura, v. 3, n.1, p. 07-17.

STAINBACK, S.; STAINBACK, W. (1999). Inclusão: um guia para educadores. Porto Alegre: Artmed, 1999.

Submetido em: 10/04/2014

Aceito em: 08/05/2019 